\title{
Is Decompressive Craniectomy is an effective method in treatment of brain swelling in traumatic brain injury
}

\author{
Mostafa Kamel El Fouly, MD. \\ Department Of Neurosurgery El sahel Teaching hospital, Cairo, Egypt.
}

\begin{abstract}
:
Background: Decompressive craniectomy is considered a line of treatment strategy that indicated after failure of conservative management.

Aim of work :to detect the effectiveness of decompressive Craniotomy as treatment of brain swelling in traumatic brain injury Methods: A cross-sectional study was employed including 20 patients of severe closed head injury in age between 18 and 48 years old operated with decompressive craniectomy and duraplasty. All patients had Glasgow coma score 4 to 8. We follow up the cases at least 6 months following Glasgow outcome scale score. Results: The poor outcome were reported with score 1, 2 and 3 (death, vegetative and severe disability in 35\% of cases, while good prognosis are reported in score 4 and 5 (moderate, mild or no disability). The outcome is better with younger patient, high Glasgow coma score, low intracranial pressure and presence of papillary reflex. Conclusion: .Decmpressive craniotomy and duraplasty is a safe procedure that correct the intercranial, so improving the outcome. It is recommended for cases of severe head injury with cerebral swelling in CT scan and medically refractory intracranial hypertension with clinical deterioration neurologically.
\end{abstract}

Conflict of interest: The authors declare that they have no conflict of interest.

Funding: This research did not receive any specific grant from any funding agency in the public, commercial or not-for-profit sector.

Keywords: Brain edema, intracranial pressure, papillary reaction, craniectomy, and head trauma.

\section{Introduction}

Several modes of management has been applied in cases of intracranial hyper tension like the use of osomotic diuretic, sedation, hyperventilation, hypothermia, maintain of oxygenation and drainage of cerebrospinal fluid by venticulostomy (15). The adverse effects of intracranial hypertension are due to compression of the brain as well as impairment of cerebral blood flow. Decomprssive craniectomy reduces this pressure and enhances blood flow (14). Cerebral edema and intracranial hypertension are present in many several neurological condition including traumatic brain injury. The impaired cerebral perfusion resulting from increased intracranial pressure leading to cell death (15). These measures are not always effective . So more aggressive treatment are indicated (13). Traumatic intracranial lesion may lead to refractory intracranial hypertension and subsequent brain death despite a well conducted medical treatment (5). Decompressive craniectomy is thought to be a potential option in these instances. Decompression craniectomy refer to removal of an area of skull in order to enhance the potential volume of intracranial compartment (3). In experimental methods of traumatic brain injury it has been demonstrated that decompressive craniectomy decrease post traumatic intracranial pressure, improve cerebral perfusion, reduce secondary brain damage, and improve survival and functional outcome. These effects are thought be the result of increase in collateral circulation, reduction in tissue edema, improvement in oxygenation and energy metabolism (4).

Aim of work : To detect the effectiveness of decompressive craniotomy as treatment of brain swelling in traumatic brain injury.

\section{Methods}

A cross-sectional study was employed, In this study 20 patients with severe head injury managed by decompressive craniectomy in Riyadh Care hospital and in Najd Consulting hospital in Saudi Arabia the period from may 2010 till February 2012. Informed Consent was obtained from relative after explanation of the method of surgery and risks for all cases. In this study all operation were done within 48 hours and all patient were monitored preoperative by intra ventricular or intraparenchymal catheter to measure intracranial pressure. All patients had intracranial pressure more than $30 \mathrm{mmHg}$ preoperative. All patients were managed conservatively first and the decision of surgery was taken when there was no improvement or deterioration neurologically and no improvement or increase in intracranial tension. We start first ted fixed by haemodynamic stabilization, elevation of the head 30 degree, sedation, normothemia, hyperventilation, (Pco2 30-35 $\mathrm{mmHg}$ ), osmotherapy with mannitol $0.25-1 \mathrm{~g} / \mathrm{kg}$. Inclusion criteria were GCS 8 Or less, unilateral brain swelling with 
midline shift, intracranial pressure more than $30 \mathrm{mmHg}$ and age less than 50 years. Exclusion criteria patient with poor neurologic condition with residual disability, bilateral absence of papillary response, GCS 3 and the surgical procedure was a unilateral decompressive craniectomy at least $9 \mathrm{~cm}$. Unilateral frontotemporal parietal free bone flap was removed. Care was taken to avoid venous sinuses. Dura was opened with an emptying of the exta axial collection. Dura was enlarged with dural graft. The bone was kept with antibiotic in refrigator in blood bank for replacement later on after 4 to 6 months by cranioplasty surgery. All patient has follow up with clinical evaluationand CT scan of at least 6 months after decomprssivrse surgery .W e depend on Glasgow outcome scale score in follow up of the cases , 1 (death), 2 (vegetative state), 3 (severe disability), 4 (moderate disability) and 5 (mild or no disability).

\section{Results}

Table (1): Description of the study group

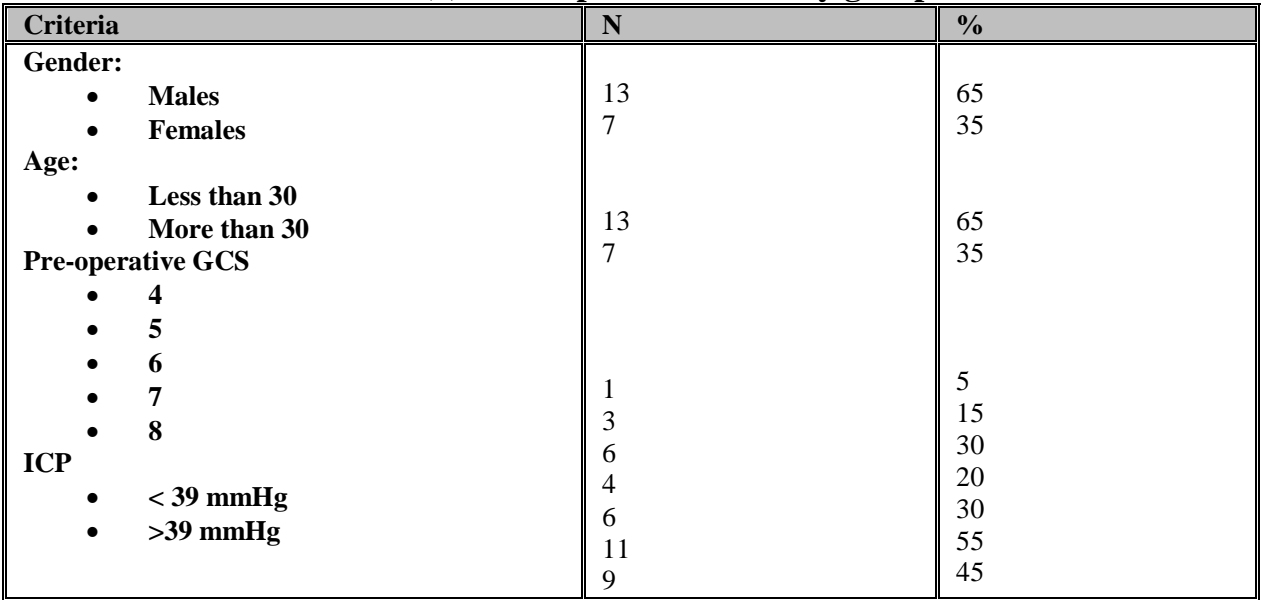

This table shows that most of the study group were males, the age of the study group was above and below 30 equally, the majority with GCS either 6 or 8 and more than half of them had preoperative ICP more than 39 $\mathrm{mmHg}$.

Table (2): Frequency distribution of the clinical criteria of the study group

\begin{tabular}{|c|c|c|}
\hline Criteria & $\overline{\mathrm{N}}$ & \% \\
\hline \multicolumn{3}{|l|}{ Unilateral papillary response: } \\
\hline - $\quad$ Present & 12 & 60 \\
\hline - Absent & 8 & 40 \\
\hline \multicolumn{3}{|l|}{ Medline shift in CT: } \\
\hline$<\quad<5 \mathrm{~mm}$ & 8 & 40 \\
\hline - $\quad>5 \mathrm{~mm}$ & 12 & 60 \\
\hline \multicolumn{3}{|l|}{ Complications: } \\
\hline - Present & 10 & 50 \\
\hline - Absent & 10 & 50 \\
\hline \multicolumn{3}{|l|}{ Type of complications: } \\
\hline - Subdural effusion & 1 & 5 \\
\hline - $\quad$ Meningitis & 1 & 5 \\
\hline - $\quad$ Encephalitis & 1 & 5 \\
\hline - $\quad$ Sunken skin at the site of surgery & 4 & 20 \\
\hline - $\quad$ Hemiparesis & 2 & 10 \\
\hline \multicolumn{3}{|l|}{ Outcome GCS: } \\
\hline$\bullet \quad 1$ & 2 & 10 \\
\hline - 2 & 1 & 5 \\
\hline - 3 & 4 & 20 \\
\hline - 4 & 3 & 15 \\
\hline - 5 & 10 & 50 \\
\hline
\end{tabular}

This table shows that most of the patients had unilateral papillary response, with Medline shift more than $5 \mathrm{~mm}$, complications present in half of them, the most frequent complications were hemiparesis and death, in addition half of them had GCS equal 5. 
Table (3): Relation between outcome GCS and some factors

\begin{tabular}{|c|c|c|c|c|c|c|c|}
\hline \multirow[t]{2}{*}{ GCS } & \multicolumn{2}{|c|}{ Poor } & \multicolumn{2}{|c|}{ Good } & \multirow[t]{2}{*}{ Total } & \multirow[t]{2}{*}{$\overline{X^{2}}$} & \multirow[t]{2}{*}{$\mathbf{p}$} \\
\hline & $\mathbf{N}$ & $\%$ & 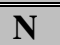 & $\%$ & & & \\
\hline $\begin{array}{l}\quad \text { ICP } \\
<39 \mathrm{mmHg} \\
>39 \mathrm{mmHg} \\
\end{array}$ & $\begin{array}{l}1 \\
6\end{array}$ & $\begin{array}{l}14.3 \\
85.7\end{array}$ & $\begin{array}{l}10 \\
3\end{array}$ & $\begin{array}{l}76.9 \\
23.1\end{array}$ & $\begin{array}{l}11 \\
9\end{array}$ & 7.2 & $0.007 *$ \\
\hline $\begin{array}{l}\text { Present } \\
\text { Papillary reflex } \\
\text { Absent }\end{array}$ & $\begin{array}{l}2 \\
5\end{array}$ & $\begin{array}{l}28.5 \\
71.5\end{array}$ & $\begin{array}{l}10 \\
3 \\
\end{array}$ & $\begin{array}{l}76.9 \\
23.1\end{array}$ & $\begin{array}{l}12 \\
8\end{array}$ & 4.4 & $0.03 *$ \\
\hline $\begin{array}{l}\begin{array}{c}- \text { Age } \\
<30 \text { years }\end{array} \\
>30 \text { years }\end{array}$ & $\begin{array}{l}2 \\
5\end{array}$ & $\begin{array}{l}28.5 \\
71.5\end{array}$ & $\begin{array}{l}11 \\
2\end{array}$ & $\begin{array}{l}84.6 \\
15.4\end{array}$ & $\begin{array}{l}13 \\
7\end{array}$ & 6.2 & $0.01 *$ \\
\hline $\begin{array}{l}\quad \text { Medline Shift } \\
<5 \mathrm{~mm} \\
>5 \mathrm{~mm}\end{array}$ & $\begin{array}{l}3 \\
4\end{array}$ & $\begin{array}{l}42.8 \\
57.2\end{array}$ & $\begin{array}{l}5 \\
8\end{array}$ & $\begin{array}{l}38.4 \\
61.6\end{array}$ & $\begin{array}{l}8 \\
12\end{array}$ & 0.3 & 0.8 \\
\hline Total & 7 & 100 & 13 & 100 & 20 & & \\
\hline
\end{tabular}

This table shows that most of patients with low preoperative ICP had good prognosis in contrast to those with high preoperative ICP. Also, good prognosis was higher among those <30 years with present papillary reflex. While, Medline shift had no effect on the outcome GCS.

\section{Discussion}

Decompression craniectomy is a procedure in the treatment of refractory intracranial hypertension which is accompanied by massive edema brain swelling (10).

The advantage of decompressive craniectomy has over more conservative approach to ICP control are thought to be due to rapid and generally permanent decline in ICP and maintainance of neurological status(12) .Some authors reported a statistically significant decrease in ICP from $32 \mathrm{~mm} \mathrm{hg}$ to $21 \mathrm{~mm}$ hg after decompressive craniectomy and duraplasty in adult patient (11). Other studies report decrease ICP from $42 \mathrm{~mm}$ hg as a mean ICP preoperative to $21 \mathrm{~mm} \mathrm{hg}$ as a mean postoperative ICP who underwent decomprssive craniectomy and duraplasty to treat severe traumatic brain injury(7). The fact that a minimum of two surgical procedure are required, the first is removal of bone flap and the second to repair the defect (cranioplasty) is a potential cause of concern since the later has been associated with a number of complication. It is necessary that in taking decision to operate, the risk of complication should be weighted against the potential benefit of the procedure (1).

Approximately half of head injured patients with score 7 or less has a significantly elevated intracranial pressure (8). In other studies reported that patients GCS 5 or less $57.89 \%$ developed high ICP and those with 6 and 7 GCS $54.16 \%$ developed high ICP ,while those with 8 GCS only $10 \%$ develop increase in intracranial tension (9).

Some studies reported that decompressive craniectomy should be performed as soon as ICP value remains more than $30 \mathrm{~mm}$ hg (2). In this study all our cases had intracranial pressure more than $30 \mathrm{~mm}$ hg. The mean intracranial pressure in our study was $39.6 \mathrm{~mm}$ hg. In our study we choose cases of adult type between 18 and 50 years. We avoid entering pediatric group in this study who respond in different way, also we avoid patient more than 50 years who had a worse prognosis. In this study the mean age was 30.5 year. In this study male were $65 \%$.In this study we choose only patients who has GCS 8 or below. The mean GCS in this study was 6.55 . In this study the absence of unilateral absence of papillary reflex was present in $35 \%$ of cases. In this study we choose on the cases with unilateral diffuse brain swelling with midline shift which is more than $5 \mathrm{~mm}$ in $40 \%$ of cases. In this study we divide the outcome of the cases to two group, the first group poor outcome (Glasgow outcome score 1, 2 and 3) which was present in 35\%.The second group with good outcome (Glasgow coma score 4 and 5) which was represent $65 \%$.The mean age in the first group is 38.14 year, while the mean age in the second group was 26.38 . This was going with the better result with younger age. Also we reported the mean GCS before surgery in the first group was 5.42, while in the second group was 7.15. This is going with the better results with cases with higher GCS preoperatively. Also we found unilateral absence of papillary response and midline shift more than $5 \mathrm{~mm} \mathrm{hg}$ in the first group in $85.6 \%$ of cases, while those finding was present in the second group in $15.4 \%$ of cases. This is going with better prognosis when midline shift is less than $5 \mathrm{~mm}$ and when papillary response is present. Decompressive craniectomy is a life saving procedure especially in 
young patient without brain stem dysfunction. This procedure could avoid cerebral herniation related to intracranial hypertension because of brain edema (6).

\section{Conclusion}

In head trauma patients with intracranial hyper tension refractory to medical treatment and at very high risk of subsequent brain death decompressive craniectomy is life saving measure in attempt protect the brain from damaging effect of propagating edema and intracranial hypertension . Proper patient selection and optimizing time of the procedure may be expected to further improvement in the outcome in severely brain injury patients. Decmpressive craniectomy and duraplasty is a safe procedure that correct the ICP, so improving the outcome. It is recommended for cases of severe head injury with cerebral swelling in CT scan and medically refractory intracranial hypertension with clinical deterioration neurologically.

\section{Acknowledgements}

We wish to thank all patients for their cooperation and help.

\section{References}

[1]. Chang V., Hartzfeld P., Langlois M., Mahmood A. and Seyfried D.: Outcome of cranial repair after craniectomy .Avalable from : http//www.ncbi.nlm. nib. gov/pubmed/19612971, J . Neurosurgery, 2009.

[2]. De Luca G.P., Volpin L., Fornezza U. et al.: The role of decompressive craniectomy in treatment of uncontrollable posttraumatic intracranial hypertension. Acta Neurochir. Suppl , 76:4o1-404, 2000.

[3]. Guerra W.K.,Gaah M.R.,Dietz H., Mueller J., Picck J., and Fritsch M.J. :Surgical decompression for traumatic brain swelling, indication and results . J. Neurosurgery, $90: 187-196,1999$.

[4]. Huchinson P.,Timofeev I., and Kirkpatrick P. : Surgeryfor brain edema : decompressive craniectomy . Available from ; http:/www. medscape .com /viewarticle/ 559009_2), 2007.

[5]. Jacques A., et al.:Brain Trauma Foundation :Americation Association of Neurological Surgeons .Joint Selection on Neurotrauma and Critical Care : Initial management .J. Neurotauma, 17:463-469, 2000.

[6]. Jaques A., Marc L., Jean R.A. et al. :Decopressive craniectomy for severe traumatic brain injury . Neurologic Critical Care, 31 No $10: 2535-2538,2003$.

[7]. Kunze E., Meixensberger j.,Janka M.,et al. :Decopressive craniectomy in patients with uncontrollable intracranial hypertension . Acta

[8]. Marshall L.F.and Marshall S.B. :Outcome prediction in severe head injury In ; Wilikins R.H. and Rengachary S.S. , Neurosurgery, New York, Mc Graw- Hill, pp 2717-2721, 1996.

[9]. Moustafa M., Nigm N., et al. : Value of ICP monitoring in the nanagement of head injury . Sci. Med. J. Escme , vol . 10, No 3, July, 1998.

[10]. Pick J.: Decompressive surgery in the treatment of traumatic brain injury .Curr Opin Crit Care,8 : 134-138,2002 .

[11]. Polin R.S.,Shaffery M.E.. Pogaev C. A., et al.: Decopressive bifrontal craniectomy in the treatment of severe refractory post traumatic cerebral edema . Neurosurgery , 41:84-94, 1997.

[12]. Polin R.S., Ayad M. and Jane J. A. Decompessive craniectom in pediatric patients Crit. Care . 7:409-410, 2003 .

[13]. Reddy A.K.,Saradhi V., Panigrahi M., Rao T.N.,Tripathi P., Meena A.K.: Decompessive craniectomyfor stroke indication and results . Neurol. India ,50:66-69, 2002.

[14]. Skoglund TS., Eriksson Ritzen C., Jensen C., Rydenhag B.: Aspect on decompressive craniectomy in patients with traumatic head injury. J. Neurotrauma, $23: 1502-1559,2006$.

[15]. Van Veen E.,Aerdts S., Van Den Brink W.1: Decompressive hemicraniectomy for refractory intracranial hypertension after traumatic brain injury. Critical Care, $10: 458,2006$. 